\title{
Does Drilling Induce Hearing Loss after Modified Radical Mastoidectomy? A Retrospective Study
}

\section{Yogesh Neupane, Bijaya Kharel, Heempali Dutta}

Department of ENT-HNS, Maharajgunj Medical Campus, Ganesh Man Singh Memorial Academy of ENT - Head \& Neck Studies, Tribhuvan University Teaching Hospital, Maharajgunj, Kathmandu, Nepal

\section{Corresponding author:}

\section{Bijaya Kharel, MBBS, MS}

Department of ENT-HNS, Maharajgunj Medical Campus, Ganesh Man Singh Memorial Academy of ENT - Head \& Neck Studies, Tribhuvan University Teaching Hospital, Maharajgunj, Kathmandu, Nepal

Email: bijayaasim@gmail.com

Submitted : Oct 9, 2020

Accepted : Nov 28, 2020

\begin{abstract}
Introduction

Incidence of sensory neural hearing loss following mastoid surgery varies from $1.2-4.5 \%$.There are various causes for postoperative sensorineural hearing loss during mastoid surgery. This study aims to identify whether there is any correlation between drilling and postoperative sensory neural hearing loss.

\section{Methods}

A retrospective study was conducted in the Department of ENT from January 2018 to June 2019. A total number of 68 patients above five years of age who underwent modified radical mastoidectomy for chronic otitis media squamous were included. Revision surgery, preoperative sensorineural hearing loss, injury to the ossicular chain during surgery, patients with lack of follow up or doubtful reports in mentally challenged were excluded from the study. The average bone conduction threshold was calculated from 500, 1000, 2000, $4000 \mathrm{~Hz}$ and compared using the Wilcoxon signed-rank test.
\end{abstract}

\section{Results}

There were 43 males and 25 females in the study with a median age of 23.5 years (16-55). The mean preoperative bone conduction threshold in the four frequencies of $500 \mathrm{~Hz}, 1 \mathrm{kHz}, 2 \mathrm{kHz}, 4 \mathrm{kHz}$ were $-2.06 \mathrm{~dB}$, $-2.06 \mathrm{~dB}, 3.31 \mathrm{~dB}, 4.63 \mathrm{~dB}$ respectively and the mean postoperative bone conduction thresholds were 1.03, $1.32,5.29,4.04$ respectively. There was a decline of mean of $3.09 \mathrm{~dB}$ and 3.38dB only at the low-frequencies $(500 \mathrm{~Hz}$ and $1 \mathrm{kHz}) \mathrm{BC}$ threshold respectively which were statistically significant, whereas at higher frequency there was no decline in average postoperative BC threshold.

\section{Conclusion}

There is no definite role of drill in inducing hearing loss and if present other causes of hearing loss should be sought in postoperative sensorineural hearing loss.

\section{Keywords}

Drill, mastoidectomy, noise-induced hearing loss 


\section{INTRODUCTION}

$(2$ hronic otitis media is a public health problem and a common cause of hearing impairment. ${ }^{1}$ Different modifications of mastoidectomy are used in surgery for chronic otitis media squamous. The incidence of sensory neural hearing loss following mastoid surgery varies from $1.2-4.5 \% .^{2}$ There are various proposed surgical and diseaserelated factors for sensorineural hearing loss after mastoidectomies. These include the experience of the surgeon, the excessive manipulation of the ossicular chain, the inadvertent opening of the vestibule, aggressive removal of disease over preexisting hidden fistula, and acoustic trauma from drill or from the suction to the cochlea.,4 The noise generated while drilling exposes cochlea to hazardous noise levels of about $100 \mathrm{~dB}$ in the operated ear with up to $10 \mathrm{~dB}$ lower levels on the contralateral side. 5,6 Similarly, suction can induce noise up to $90 \mathrm{~dB} .^{7}$ Exposure to these high-intensity loud noises for a prolonged time is harmful to the hair cells and leading to sensorineural hearing loss (SNHL). Some patient-related predisposing factors are susceptibility to noise-induced damage, elderly patients, and comorbidities. Depending upon the duration, it can be a temporary threshold shift or a permanent threshold shift. ${ }^{5,8}$ There is a possible chance of threshold shift but in clinical scenarios, there are conflicting results. ${ }^{8}$ Acoustic damage by drilling during mastoid surgery causing SNHL is still debatable. This study aims to identify the possible relationship between drilling and hearing loss after modified radical mastoidectomy.

\section{METHODS}

This retrospective study was conducted in the Department of ENT \& Head Neck Surgery, Tribhuvan University Teaching Hospital from January 2018 to June 2019. A total number of 68 patients above 5 years of age, including all genders who underwent modified radical mastoidectomies for chronic otitis media squamous by faculties under general anesthesia, were included. Patients who underwent previous mastoid surgery, patient with preoperative sensorineural hearing loss, grievous injury to the ossicular chain during surgery causing postoperative sensorineural hearing loss, the patient who did not follow-up for postoperative hearing assessment after $10^{\text {th }}$ week, and mentally challenged patients whose audiometric report were doubtful were excluded from the study.

Otoscopic ear findings, tuning fork test with $512 \mathrm{~Hz}$, High resolution Computed Tomography temporal bone findings, and pure tone audiometry (PTA) findings were noted from record files. PTA was performed within one week prior to surgery and after 10 to 12 weeks of surgery. Hugan and Westlake technique was used for audiometric evaluation and performed with $5 \mathrm{~dB}$ intensity interval. Air conduction included 250, 500, 1000, 2000, 4000, and $8000 \mathrm{~Hz}$. Bone conduction (BC) included 250, 500, 1000, 2000, and $4000 \mathrm{~Hz}$ which was used for analysis. The average was calculated from 500, 1000, 2000, $4000 \mathrm{~Hz}$ frequencies.

All cases of mastoidectomies were performed by experienced ENT and Head Neck surgeons. In most cases, in to out techniques were used except for a few where out to in was used according to the comfort of the surgeons during surgery. NSK Volvere $V$ max micromotor system with a speed range of 1000 to $35000 /$ min was used for drilling. Meatoplasty was done and the mastoid cavity was packed with ribbon gauze impregnated with BIPP or antibiotic- steroid ointment which was removed on the $10^{\text {th }}$ POD. Topical antibiotics and steroid ear drops were given for 1 month after removal of the ear pack. PTA was repeated after the 10th postoperative week and recorded. The data were analyzed using SPSS version 25.0 software. Wilcoxon signed-rank test was used for the statistical analysis. Statistical significance was taken at 95\% confidence interval with p-values of $<0.05$.

\section{RESULTS}

There were 43 males and 25 females in the study. The median age of the patients was 23.5 years with a range of $16-55$ years.

The mean preoperative bone conduction thresholds in the four frequencies of $500 \mathrm{~Hz}, 1 \mathrm{kHz}, 2 \mathrm{kHz}, 4 \mathrm{kHz}$ were $-2.06 \mathrm{~dB},-2.06 \mathrm{~dB}, 3.31 \mathrm{~dB}, 4.63 \mathrm{~dB}$ respectively (Table 1). The mean postoperative bone conduction thresholds were 1.03, 1.32, 5.29, and 4.04, respectively, at different ascending frequencies. The maximum change in postoperative bone conduction threshold was seen in $1 \mathrm{kHz}$ followed by $500 \mathrm{~Hz}$ (Figure 1). Only in the low frequencies $(500 \mathrm{~Hz}$ and 1 $\mathrm{kHz}$ ), BC threshold had a postoperative change that was statistically significant with a p-value of 0.001 (Table 1). However, the results were not statistically significant in the higher frequency sound $(2 \mathrm{kHz}, 4$ $\mathrm{kHz}$ ). Moreover, at the frequency of $4 \mathrm{kHz}$, instead of the decline in BC threshold, there is almost a similar or even slight improvement seen.

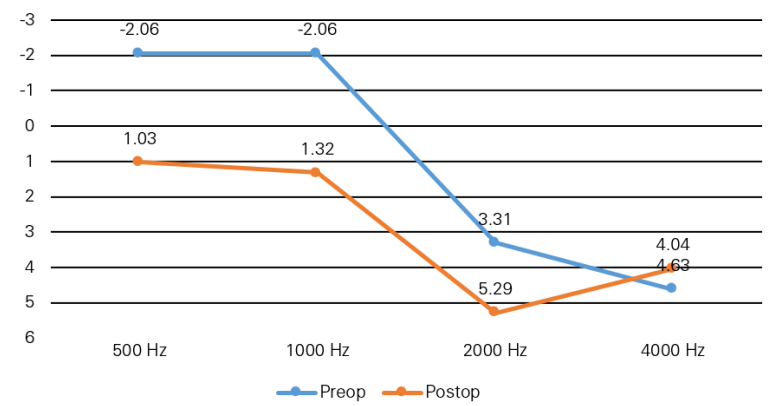

Fig 1. Line diagram of preoperative and postoperative bone conduction at different frequencies 
Table 1. Comparison of the mean of preoperative and postoperative bone conduction threshold at different frequencies

\begin{tabular}{lccccc}
\hline Frequency & Mean & SD & z-value & p-value & $\begin{array}{c}\text { Mean change } \\
\text { (Postop BC-Preop BC) }\end{array}$ \\
\hline Preop $500 \mathrm{~Hz}$ & -2.06 & 7.60 & -3.19 & 0.001 & 3.09 \\
Postop $500 \mathrm{~Hz}$ & 1.03 & 9.17 & & & 3.38 \\
Preop $1 \mathrm{kHz}$ & -2.06 & 7.79 & -3.38 & 0.001 & \\
Postop1 kHz & 1.32 & 9.09 & & & 1.98 \\
Preop $2 \mathrm{kHz}$ & 3.31 & 10.28 & -1.79 & 0.07 & \\
Postop $2 \mathrm{kHz}$ & 5.29 & 10.14 & & & -0.59 \\
Preop $4 \mathrm{kHz}$ & 4.63 & 10.27 & -0.613 & 0.5 & \\
Postop $4 \mathrm{kHz}$ & 4.04 & 8.86 & & & \\
\hline
\end{tabular}

At the frequency of $500 \mathrm{~Hz}, 60.29 \%$ (41/68) of patients showed either no change or improvement when compared with the preoperative level, whereas $39.71 \%(27 / 68)$ of cases showed decreased bone conduction following mastoidectomy. Among the cases with impairment, 30.9\% (21/68) showed impairment up to $10 \mathrm{~dB}, 7.35 \%$ (5/68) showed hearing impairment up to $20 \mathrm{~dB}, 1.47 \%(1 / 68)$ showed impairment of more than $20 \mathrm{~dB}$ (Figure 2).

Similarly, at the frequency of $1 \mathrm{kHz}$, there were no postoperative BC changes seen in 58.82\% (40/68) of patients when compared with preoperative level. Bone conduction threshold was impaired in $41.18 \%$ $(28 / 68)$ cases out of which $33.82 \%(23 / 68)$ showed decline up to $10 \mathrm{~dB}, 5.88 \%$ (4/68) showed hearing decline up to $20 \mathrm{~dB}, 1.47 \%$ (1/68) showed decline more than $20 \mathrm{~dB}$ (Figure 2).

There was no postoperative change at the frequency of $2 \mathrm{kHz}$ in $67.65 \%(46 / 68)$ cases. Nearly $22.06 \%$ $(15 / 68)$ showed a decline up to $10 \mathrm{~dB}$, whereas 8.82 $(6 / 68)$ cases showed a decline up to $20 \mathrm{~dB}$ and only $1.47 \%(1 / 68)$ showed impairment up to $20 \mathrm{~dB}$. At 4 $\mathrm{kHz}$ frequency in $79.41 \%(54 / 68)$ cases, there was no decline seen. A decline up to $10 \mathrm{~dB}$ was seen in $11.76 \%(8 / 68)$ cases and up to $20 \mathrm{~dB}$ in $8.82 \%$ (6/68) cases.

\section{DISCUSSION}

Mastoid bone drilling is a crucial step in the clearance of disease in otologic surgery. Drilling during mastoidectomy exposes the inner ear to the high intensity of noise level of about $100 \mathrm{~dB}$ (range $65 \mathrm{~dB}-117 \mathrm{~dB}$ ) as shown by various clinical studies and temporal lab dissection studies.5,6 The intensity of noise generated depends on various parameters including rotation speed, type of burr, burr size, and site of drilling (a solid area or aerated area).9 Mastoid drilling with larger size $(6 \mathrm{~mm}$ cutting) burr generates an intensity of 88 to $108 \mathrm{~dB}$, whereas there is further noise reduction with decreased burr size and the maximum reduction is seen with the small $2 \mathrm{~mm}$ burr (up to $16 \mathrm{~dB}$ ). ${ }^{9}$ The sound pressure level produced by the cutting burr is more than the levels of the diamond burr, so, in vital structures diamond burr is advised. ${ }^{10,11}$ High-speed drill produces a low noise level causing less damage to hair cells of the cochlea and is safer compared to the low-speed drill that generates the highest intensity sound. ${ }^{9}$ The risk of sensorineural hearing loss is increased when drilling the ossicular chain directly or after an inadvertent touch.12 The intensity is low in the aerated mastoid air cells and higher in solid bones and ossicles. Drill-induced noisy sound has been suspected as a cause of about $5 \mathrm{~dB}$ SNHL in

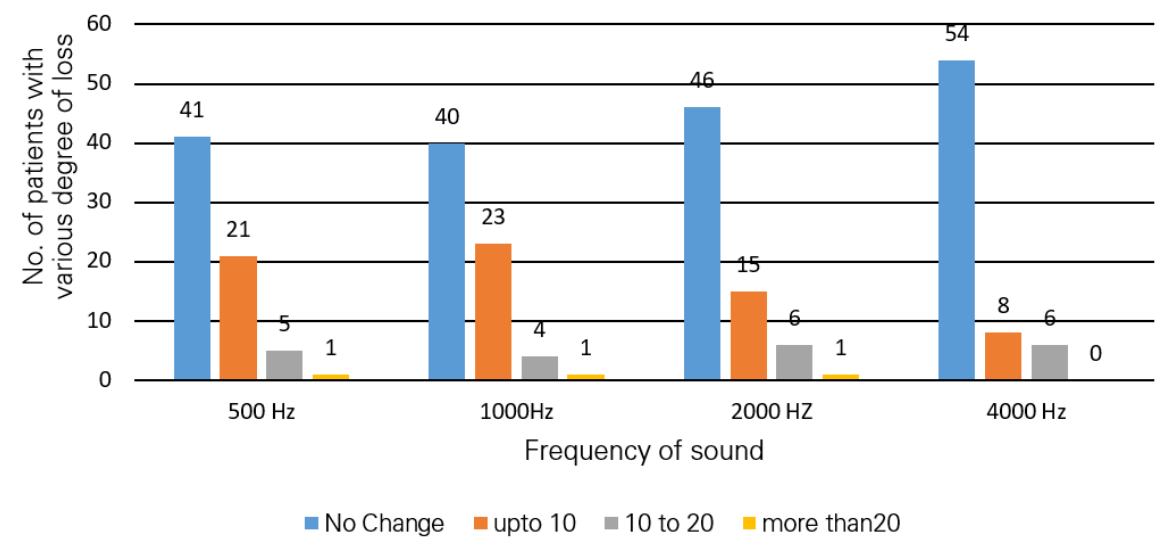

Fig 2. Degrees of change in bone conduction threshold level between preoperative and postoperative status at different frequencies 
all frequencies in mastoidectomy (range $3 .^{1}$ and 6.6 dB). ${ }^{9}$ This is similar to our study where there is a decline in $3 \mathrm{~dB}$ compared to preoperative status in lower frequencies (Figure 1).

In our study, there was statistically significant hearing loss at a lower frequency of $500 \mathrm{~Hz}$ and $1 \mathrm{kHz}$ only but not at the higher frequencies. This finding is peculiar and in contrast to the current evidence that noise-induced hearing loss occurs most frequently in the higher frequency. Even though the finding on low frequency was significant but it was only within $3 \mathrm{~dB}$ range and was not clinically significant. There are multiple possible reasons for the insignificant reduction of the bone conduction threshold in this study. As the surgery performed by senior faculty was included, there was a reduction in operation time of surgery (drilling time), which could have prevented the prolonged exposure to loud noise. The practice of incudostapedial joint disarticulation prior to the drill during in to out technique prevents transmission through the ossicles. Judicious use of diamond burr over vital structures, using smaller size burr in crucial areas, and preventing inadvertent ossicular damage might be the other reasons.

There have been some conflicting results with the drill-induced hearing loss.,11 Although the intensity of noise produced during drilling is high and above a safety level, the intermittent nature of the drilling during a mastoidectomy may allow the ear sufficient time to recover. ${ }^{12}$ Moreover, constant saline irrigation during drilling may dampen the intensity of the sound. According to Iranfar et al., sensorineural hearing loss is temporary only. ${ }^{13}$ There can be a change in temporary hearing threshold which recovers spontaneously within 72-96 $\mathrm{h}$ postoperatively. ${ }^{14}$ In this study, hearing assessment was done after 10 weeks of surgery so the chances of temporary threshold shift could have been missed. The temporary threshold shift has no clinical value as this gets normalized before the ear pack is removed from patients' operated ear.

Schuknecht et al. suggest that drilled noise does not give rise to a risk of inner ear injury (SNHL) and is within safe limits. ${ }^{15}$ Similar findings were seen in other studies that failed to show any adverse effects of the noise generated by the drill on the hearing function. 8,16

The positive aspect of the study is that the revision cases and cases performed by the residents were excluded. Inadvertent damage done by the young surgeon as well as the longer operative time could alter the results and this should be considered in cases with SNHL. The small sample is a potential limitation of this study. A prospective study with larger sample size and a longer follow-up is advised.

\section{CONCLUSION}

There is no definite role of drill in inducing sensorineural hearing loss. Although the loud noise of the drill can possibly lead to a temporal threshold shift, but the study fails to show any changes in the permanent threshold shift. In the events of postsurgery sensorineural hearing loss, some other complications related to surgery, including the labyrinthine injury (labyrinthitis) and major ossicular disruption should be excluded first.

\section{CONFLICT OF INTEREST}

None declared.

\section{REFERENCES}

1. Mackenzie I, Smith A. Deafness-the neglected and hidden disability. Ann Trop Med Parasitol 2009. Oct;103(7):565-71

2. Paulose AA, Kumar A, Sonkhya N. Post Operative Sensorineural Hearing Loss Following Middle Ear Surgery—A Study of 100 Cases. Int J Otorhinolaryngol Head Neck Surg. 2018 May;7(3):67.

3. Al Anazy FH, Alobaid FA, Alshiha WS. Sensorineural hearing loss following tympanoplasty surgery: A prospective cohort study. Egypt J Otolaryngol. 2016 Apr;32(2):93-7.

4. Man A, Winerman I. Does drill noise during mastoid surgery affect the contralateral ear? Am J Otol 1985 Jul;6(4):334-5.

5. Kylén $P$, Arlinger $S$. Drill-generated noise levels in ear surgery. Acta Otolaryngol 1976 Nov;82(1-6):402-09.

6. Lee HK, Lee EH, Choi JY et al. Noise level of drilling instruments during mastoidectomy. Yonsei Med J 1999 Aug;40(4):339-42.

7. Jang $\mathrm{CH}$, Song $\mathrm{CH}$, Kim SH et al. Influence of suction tube noise on hearing in pediatric patients who received ventilation tube insertion. Chang Gung Med J 2004 Oct;27(10):734-40.

8. Urquhart AC, McIntosh WA, Bodenstein NP. Drill-generated sensorineural hearing loss following mastoid surgery. Laryngoscope. 1992 Jun; 102(6):689-92.

9. Paksoy M, Sanli A, Hardal U et al. How drill-generated acoustic trauma effects hearing functions in an ear surgery. Int J Head Neck Surg. 2012;3(3):127-32.

10. Dalchow $C V$, Hagemeier $\mathrm{KC}$, Muenscher A et al. Investigation of noise levels generated by otologic drills. Eur Arch Oto-Rhino-L. 2013 Feb;270(2):505-10.

11. Latheef MN, Karthikeyan P, Coumare VN. Effect of Mastoid Drilling on Hearing of the Contralateral Normal Ear in Mastoidectomy. Indian J Otolaryngol. 2018 Jun;70(2):205-10.

12. Helms J. Acoustic trauma from the bone cutting burr. J Laryngol Otol. 1976 Dec;90(12):1143-9.

13. Iranfar K, Iranfar S. Does surgery of chronic otitis media cause sensori neural hearing loss. Pak J Med Sci. 2009 Oct ;25(6):972-5.

14. Karatas E, Miman MC, Ozturan 0 et al. Contralateral normal ear after mastoid surgery: evaluation by otoacoustic emissions (mastoid drilling and hearing loss). ORL J Oto-Rhino-Laryngol Relat Spec. 2007 69(1):18-24.

15. Schuknecht HF, Tonndorf J. Acoustic trauma of the cochlea from ear surgery. The Laryngoscope. 1960 Apr;70(4):479-505.

16. Tos M, Trojaborg N, Thomsen J. The contralateral ear after translabyrinthine removal of acoustic neuromas: Is there a drillnoise generated hearing loss? J Laryngol Otol 1989 Sep;103(9): 845-9. 